\title{
QUALIDADE INDUSTRIAL DO TRIGO EM FUNĈ̃̃O DO TRINEXAPAC-ETHYL E DOSES DE NITROGÊNIO ${ }^{1}$
}

\author{
Industrial quality of wheat as a function of trinexapac-ethyl and nitrogen doses ${ }^{1}$
}

\author{
Luis Henrique Penckowski², Jeferson Zagonel ${ }^{3}$, Eliana Cuéllar Fernandes ${ }^{4}$
}

\begin{abstract}
RESUMO
Objetivou-se, neste trabalho, avaliar a época de aplicação do redutor de crescimento trinexapac-ethyl e de doses de nitrogênio no rendimento de grãos e qualidade industrial das cultivares de trigo Avante e BRS 177. O delineamento experimental foi blocos ao acaso em esquema fatorial 4 x 4, com quatro repetições. Os tratamentos constaram de épocas de aplicação de trinexapac-ethyl $\left(100 \mathrm{~g}\right.$ ha ${ }^{-1} \mathrm{entre}_{\mathrm{o}}$ primeiroe o segundo nó visível do trigo; $100 \mathrm{~g} \mathrm{ha}^{-1}$ entre o segundo e terceiro nó visível; aplicação sequencial de $50 \mathrm{~g} \mathrm{ha}^{-1} \mathrm{em}$ cada uma das fases anteriores; testemunha sem aplicação) e de doses de nitrogênio em cobertura (90, 135, 180 e $225 \mathrm{~kg} \mathrm{ha}^{-1}$ para a cultivar Avante e $60,80,120$ e $150 \mathrm{~kg} \mathrm{ha}^{-1}$ para a cultivar BRS 177). Avaliaram-se características agronômicas, acamamento, componentes de rendimento, rendimento de grãos, qualidade do grão e da farinha. O trinexapac-ethyl, independentemente da época de aplicação, reduziu a estatura das plantas e a porcentagem de acamamento, com resposta diferencial no rendimento de grãos e sem influência substancial na qualidade industrial do trigo. $\mathrm{O}$ aumento nas doses de nitrogênio promoveu maior acamamento, afetou a qualidade do grão e da farinha da cultivar BRS 177, mas sem efeitos no rendimento de grãos.
\end{abstract}

Termos para indexação: Triticum aestivum, redutor de crescimento, índice de queda, alveografia.

\section{ABSTRACT}

The objective of this work was to evaluate the application time of the trinexapac-ethyl growth reducer and of nitrogen rates in the yield and industrial quality of the wheat cultivars Avante and BRS 177. The experimental design was complete randomized blocks in a $4 \times 4$ factorial scheme, with four replicates. The treatments consisted of periods of trinexapac-ethyl application (100 $\mathrm{g}$ ha-1 between the first and second visible node of the wheat; $100 \mathrm{~g} \mathrm{ha}^{-1}$ between the second and third visible node; sequential application of $50 \mathrm{~g} \mathrm{ha}^{-1}$ in each one of the previous phases; without application) and of nitrogen rates in covering (90, 135, 180 and $225 \mathrm{~kg} \mathrm{ha}^{-1}$ for Avante cultivar and 60, 80, 120 and $150 \mathrm{~kg} \mathrm{ha}^{-1}$ for BRS 177 cultivar). The following characteristics were evaluated: agronomical characteristic, lodging, yield components, yield, grain and flour quality. Trinexapac-ethyl, independently of the application time, reduced plant height and the lodging percentage, with different response in the yield and without substantial influence on the industrial quality of the wheat. The increase in the nitrogen rates promoted higher lodging, affected the grain and flour quality of BRS 177 cultivar and had no effect on yield.

Index terms: Triticum aestivum, growth reducer, falling number, alveography.

\section{(Recebido em 29 de agosto de 2008 e aprovado em 16 de julho de 2009)}

\section{INTRODUÇÃO}

$\mathrm{O}$ alto potencial de produção da cultura do trigo vem sendo obtido pelo uso de cultivares modernas aliado ao uso racional e integrado dos recursos de solo, clima e técnicas de manejo. Entre as técnicas de manejo, Scalco et al. (2002) e Megda et al. (2009) destacam a adubação nitrogenada em razão do nitrogênio ser um dos nutrientes absorvidos em maior quantidade pela cultura, com respostas positivas do rendimento. Em média, são usados de 30 a $60 \mathrm{~kg} \mathrm{ha}^{-1}$ de nitrogênio aplicado em cobertura até o perfilhamento (Oliveira, 2003), sendo as menores doses recomendadas para as cultivares de porte alto e/ou para solos de alta fertilidade (Silva \& Gotto, 1990). A quantidade de nitrogênio aplicada em cultivares de alto rendimento, na região dos Campos Gerais, PR, é superior à recomendada por Oliveira (2003). Para cultivares de porte médio/baixo recomenda-se 90 a $100 \mathrm{~kg} \mathrm{ha}^{-1}$ do nutriente e para cultivares de porte alto e/ou com suscetibilidade ao acamamento, de 50 a $60 \mathrm{~kg} \mathrm{ha}^{-1}$ de nitrogênio (Pauletti \& Costa, 2002). No entanto, o uso de altas doses de nitrogênio pode resultar no aumento da estatura das plantas, com consequente acamamento que, quando ocorre na fase de enchimento de grãos, limita a translocação de carboidratos nas plantas e diminui a qualidade dos grãos (Rodrigues et al., 2003;

\footnotetext{
${ }^{1}$ Parte da dissertação do primeiro autor, apresentada à Universidade Estadual de Ponta Grossa, como parte das exigências para obtenção do grau de Mestre em Agronomia/Agricultura

${ }^{2}$ Fundação ABC - Pesquisa e Desenvolvimento Agropecuário - Rodovia PR 151 - km 288 - Cx. P. 1003 - 84165-700 - Castro, PR luishenrique@fundacaoabc.org.br

3Universidade Estadual de Ponta Grossa/UEPG - Departamento de Fitotecnia e Fitossanidade/DEFITO - Ponta Grossa, PR

${ }^{4}$ Universidade Estadual de Ponta Grossa/UEPG - Ponta Grossa, PR
} 
Zagonel \& Fernandes, 2007). Entre as estratégias de uso de altas doses de nitrogênio em trigo, para minimizar os riscos de acamamento, estão o uso de cultivares de porte baixo ou a aplicação de reguladores de crescimento.

Os reguladores de crescimentos são compostos químicos que vêm sendo utilizados como solução para o acamamento de plantas (Teixeira \& Rodrigues, 2003), sem diminuição do rendimento (Rademacher, 2000). Entre eles destaca-se o trinexapac-ethyl, um redutor de crescimento que interfere no final da rota metabólica da biossíntese do ácido giberélico (Rademacher, 2000) pela inibição da enzima 3 ß-hidroxilase, reduzindo drasticamente o nível do ácido giberélico ativo $\left(\mathrm{GA}_{1}\right)$ e assim aumentando acentuadamente seu precursor biossintético imediato $\mathrm{GA}_{20}$ (Davies, 1987). A queda no nível do ácido giberélico ativo $\mathrm{GA}_{1}$, que atua na elongação dos internódios, é a provável causa da inibição do crescimento das plantas (Rademacher, 2000).

Na Argentina, Lozano et al. (2002) verificaram que as aplicações de trinexapac-ethyl, no momento em que se observa o primeiro até o terceiro nó visível, provocaram mudanças na densidade de espigas, promovendo o desenvolvimento dos perfilhos e aumento da produção. Na Polônia, Matysiak (2006) verificou aumento de 6,5\% da produção e 2,0\% no teor de glúten do grão com o uso do trinexapac-ethyl, em ano sem déficit hídrico. No Brasil, o trinexapac-ethyl foi avaliado por Zagonel et al. (2002), que verificaram aumento do rendimento, mesmo na ausência de acamamento. Esse redutor tem sua ação dependente da época de aplicação, em que as precoces surtem pouco efeito e as tardias causam retenção de espigas, podendo causar prejuízos no rendimento de grãos (Zagonel \& Fernandes, 2007).

O uso de redutores de crescimento e da adubação nitrogenada são fatores que podem influenciar a qualidade industrial do trigo. A qualidade dos grãos é identificada por parâmetros físicos como peso do hectolitro e "Falling Number" entre outros, e na farinha de trigo os parâmetros de qualidade são principalmente químicos, reológicos e de panificação (Guarienti, 1996). O teste de "Falling Number" é utilizado para determinar a atividade da $\alpha$-amilase de grãos e farinhas (Pizzinatto, 1997). Vários autores estudaram o efeito da adubação nitrogenada (Scalco et al., 2002; Cánovas \& Trindade, 2003), de genótipos (Gutkoski et al., 2007) e de manejo do solo (Guarienti et al., 2000) na qualidade industrial do trigo. No entanto, o efeito de redutores de crescimento na qualidade do trigo foi relativamente pouco estudado. Objetivou-se, no presente trabalho, avaliar o uso de trinexapac-ethyl aplicado em diferentes épocas e de doses de nitrogênio em características agronômicas, componentes do rendimento, rendimento de grãos e qualidade industrial de duas cultivares de trigo.

\section{MATERIAL E MÉTODOS}

O experimento foi instalado no ano de 2003, no Campo Demonstrativo e Experimental da Fundação ABC, no município de Castro, PR, localizado a $24^{\circ} 51^{\prime}$ '44,35', de latitude sul, 4956'0,40" de longitude oeste de Greenwich e altitude de $1030 \mathrm{~m}$. O solo no local é um Latossolo Bruno distrófico, típico A proeminente, textura argilosa (Empresa Brasileira de Pesquisa Agropecuária - Embrapa, 2006). A análise química do solo, para amostragem de 0 a $0,20 \mathrm{~m}$, revelou os resultados: $\mathrm{pH}$ $\left(\mathrm{CaCl}_{2}\right)=5,0 ; \mathrm{Ca}^{++}=39,0 \mathrm{mmol}_{\mathrm{c}} \mathrm{dm}^{-3} ; \mathrm{Mg}=15,0 \mathrm{mmol}_{\mathrm{c}} \mathrm{dm}^{-3}$; $\mathrm{K}=2,1 \mathrm{mmol}_{\mathrm{c}} \mathrm{dm}^{-3} ; \mathrm{P}=28,0 \mathrm{mg} \mathrm{dm}^{-3} ; \mathrm{M} . \mathrm{O} .=51 \mathrm{~g} \mathrm{dm}^{-3} ; \mathrm{H}+$ $\mathrm{Al}=58 \mathrm{mmol}_{\mathrm{c}} \mathrm{dm}^{-3} ; \mathrm{Al}^{+++}=0,0 ; \mathrm{CTC}=14,7 ; \mathrm{V} \%=49$.

Utilizou-se o sistema de plantio direto, sendo soja a cultura anterior. $O$ trigo foi semeado dia 15/06/03, na densidade de 75 sementes por metro, com emergência das plantas em 25/06/03. A adubação constituiu da aplicação de $30 \mathrm{~kg} \mathrm{ha}^{-1}$ de nitrogênio, $90 \mathrm{~kg} \mathrm{ha}^{-1}$ de $\mathrm{P}_{2} \mathrm{O}_{5}$ e $60 \mathrm{~kg} \mathrm{ha}^{-1}$ de $\mathrm{K}_{2} \mathrm{O}$ na semeadura. As parcelas foram compostas de 30 fileiras de trigo de $6,0 \mathrm{~m}$ de comprimento, espaçadas de $0,17 \mathrm{~m}$. Considerou-se como área útil as vinte e quatro fileiras centrais das parcelas, desprezando-se $0,50 \mathrm{~m}$ em cada extremidade.

O delineamento experimental utilizado foi de blocos ao acaso, com dezesseis tratamentos dispostos em esquema fatorial 4 x 4 com quatro repetições. Os tratamentos constaram das combinações dos fatores: épocas de aplicação de redutor de crescimento (sem aplicação; uma aplicação de $100 \mathrm{~g} \mathrm{ha}^{-1}$ de trinexapac-ethyl entre o primeiro e o segundo nó visível - estádio 31 da escala de Zadoks et al. (1974); uma aplicação de $100 \mathrm{~g} \mathrm{ha}^{-1}$ de trinexapac-ethyl entre o segundo e o terceiro nó visível estádio 32 da escala de Zadoks et al. (1974) e duas aplicações sequenciais, a primeira com $50 \mathrm{~g} \mathrm{ha}^{-1} \mathrm{de}$ trinexapac-ethyl aplicada entre o $1^{\circ}$ e o $2^{\circ}$ nó visível e a segunda com $50 \mathrm{~g} \mathrm{ha}^{-1}$ de trinexapac-ethyl entre o segundo e o terceiro nó visível, e de doses de nitrogênio (100, 150, 200 e $250 \%$ da dose indicada para cada cultivar), na forma de uréia, aplicadas em cobertura no início do perfilhamento.

O trinexapac-ethyl foi aplicado através de pulverizador costal, à pressão constante de 206,85 kPa, pelo $\mathrm{CO}_{2}$ comprimido, com pontas de jato "leque" XR11002 VS e espaçadas de 0,5 m. O volume de calda foi de $130 \mathrm{~L} \mathrm{ha}^{-1}$.

As doses de nitrogênio em cobertura foram baseadas em experimentos realizados por Pauletti \& Costa (2002) e variaram de acordo com o porte do cultivar. Para a 
cultivar Avante, de porte médio e moderadamente resistente ao acamamento (Campos et al., 2004), as doses de nitrogênio aplicadas foram 90, 135, 180 e $225 \mathrm{~kg} \mathrm{ha}^{-1}$. Para a cultivar BRS 177, de porte alto e moderadamente suscetível ao acamamento (Embrapa, 2008), as doses de nitrogênio aplicadas foram $60,80,120$ e $150 \mathrm{~kg} \mathrm{ha}^{-1}$.

$\mathrm{Na}$ fase de antese avaliou-se a estatura das plantas, da coroa até o ápice da espiga, e o diâmetro do colmo do primeiro entrenó através da coleta de dez plantas por parcela. As avaliações de acamamento foram realizadas nas fases de antese e pré-colheita do trigo atribuindo notas de zero (sem acamamento) até $100 \%$ (parcela toda acamada). Considerou-se como planta acamada aquela que se encontrava com inclinação igual ou inferior a $45^{\circ}$, em relação ao solo. $\mathrm{O}$ rendimento de grãos do trigo foi determinado pela produção de parte da área útil de cada parcela $\left(6,12 \mathrm{~m}^{2}\right)$, corrigindo-se a umidade para $13 \%$. O número de plantas e de espigas foi determinado em uma área de $0,50 \mathrm{~m}^{2}$, escolhida ao acaso dentro de cada parcela.

A determinação da qualidade industrial foi realizada no laboratório da Bunge Alimentos, no município de Ponta Grossa, PR. Foram avaliados: peso do hectolitro; índice de queda ou "Falling Number"; quantidade de glúten úmido e seco. Os parâmetros obtidos no alveograma foram: energia de deformação da massa ou força de glúten $(\mathrm{W})$; pressão máxima de ruptura ou tenacidade $(\mathrm{P})$; extensibilidade $(\mathrm{L})$ e relação P/L. Uma descrição de tais análises pode ser encontrada em Guarienti (1996).

Os dados obtidos foram submetidos à análise de variância e, quando foram significativas as diferenças entre as médias das épocas de aplicação do trinexapac-ethyl, essas foram comparadas pelo teste Tukey, a 5\% de probabilidade. As doses de nitrogênio foram analisadas por regressão polinomial.

\section{RESULTADOS E DISCUSSÃO}

A precipitação pluvial no decorrer do experimento foi de 484,4 mm, bem distribuída desde a emergência até a maturação, condições adequadas ao desenvolvimento do trigo e para a atuação do redutor de crescimento, que tem seu efeito minimizado em condições de deficiência hídrica (Rodrigues et al., 2003; Matysiak, 2006). As características avaliadas e apresentadas nas tabelas subsequentes foram influenciadas pela aplicação de trinexapac-ethyl e pelas doses de nitrogênio, mas, não ocorreram interações significativas entre os tratamentos com o trinexapac-ethyl e o nitrogênio, para todas as variáveis analisadas.
O diâmetro do colmo da cultivar Avante não foi influenciado pelo redutor de crescimento, independentemente da época de aplicação (Tabela 1). Para a cultivar BRS 177, a aplicação do trinexapac-ethyl reduziu a espessura do colmo, principalmente para aplicação entre o segundo e o terceiro nó visível, efeito esse contrário ao encontrado por Lozano et al. (2002), em que o uso do redutor promoveu o aumento do diâmetro do colmo pelo aumento do número de feixes vasculares no primeiro entrenó e do tecido esclerenquimático no interior do colmo. A estatura das plantas diminuiu com o uso do redutor de crescimento tanto na cultivar Avante como na BRS 177, independente da época em que foi aplicado, com redução mais acentuada para a aplicação entre o segundo e o terceiro nó para a BRS 177 (Tabela 1), resultados também observados por Rodrigues et al. (2003) e Zagonel \& Fernandes (2007). As doses de nitrogênio não influenciaram o diâmetro do colmo e a estatura das plantas de ambas as cultivares (Tabela 1). Berti et al. (2007) observaram que a estatura da cultivar CEP 24 não aumentou com o incremento da dose de $\mathrm{N}$, o que evidencia que, no presente experimento, a menor dose utilizada em cada cultivar foi suficiente para suprir sua necessidade.

A redução na estatura das plantas pelo uso de redutores de crescimento é um dos fatores positivos que podem influenciar na redução do acamamento em cereais. $\mathrm{Na}$ fase de florescimento, tanto na cultivar Avante como na BRS 177 ocorreu redução do acamamento pelo uso do redutor, independente da época de aplicação (Tabela 1). $\mathrm{Na}$ fase de pré-colheita a redução da incidência de plantas acamadas causada pelo redutor foi mais acentuada na cultivar Avante, e na cultivar BRS 177 os menores índices de acamamento foram obtidos, quando se aplicou o redutor entre o primeiro e o segundo nó visível e entre o segundo e o terceiro nó visível. $\mathrm{O}$ aumento da dose de nitrogênio promoveu aumento linear do número de plantas acamadas tanto na fase de florescimento como de pré-colheita do trigo, exceto para a cultivar Avante na fase de florescimento, em que não houve efeito da dose de nitrogênio. Os resultados do presente trabalho corroboram com os de diferentes autores que observaram redução do acamamento promovida pelo trinexapac-ethyl em diferentes épocas de aplicação (Borm \& Berg, 2008), densidade de plantas (Zagonel et al., 2002), cultivares (Zagonel \& Fernandes, 2007) e altas doses de nitrogênio (Rodrigues et al., 2003).

O estande, o número de espigas por metro quadrado e a massa de mil grãos não foram influenciados pela época de aplicação do trinexapac-ethyl e pelo aumento das doses de nitrogênio, independente da cultivar (Tabela 1). Resultado semelhante foi obtido por 
Zagonel \& Fernandes (2007), que não observaram efeito do trinexapac-ethyl sobre o número de espigas por metro e espiguetas por espigas, em três cultivares de trigo. A resposta ou não dos componentes ao redutor de crescimento e/ou doses de nitrogênio pode ser explicada por fatores compensatórios como citado por Cánovas \& Trindade (2003), em que os componentes podem se relacionar de forma negativa, propiciando o incremento de uns e o decréscimo de outros, sendo o rendimento de grãos obtido pela melhor combinação dos componentes do rendimento.

Tabela 1 - Efeito do trinexapac-ethyl (TE) e do nitrogênio $(\mathrm{N})$ no diâmetro do colmo do primeiro entre-nós ( $\left.\mathrm{DC}_{1}\right)$, acamamento no florescimento (Ac. F) e pré-colheita (Ac. PC), estatura de plantas (Est.), número de plantas por $\mathrm{m}^{2}$ (Estande), espigas por $\mathrm{m}^{2}\left(\right.$ Es $\left.^{-2}\right)$, massa de mil grãos (MMG) e rendimento de grãos (Rend.) nas cultivares de trigo Avante e BRS 177.

\begin{tabular}{|c|c|c|c|c|c|c|c|c|}
\hline \multirow{2}{*}{$\begin{array}{l}\text { Tratamentos } \\
\text { Regulador de } \\
\text { crescimento }\end{array}$} & \multicolumn{8}{|c|}{ Cultivar de trigo Avante } \\
\hline & $\begin{array}{l}\mathrm{DC}_{1} \\
(\mathrm{~mm})\end{array}$ & $\begin{array}{l}\text { Est. } \\
(\mathrm{cm})\end{array}$ & $\begin{array}{c}\text { Ac. F } \\
(\%)\end{array}$ & $\begin{array}{c}\text { Ac. PC } \\
(\%)\end{array}$ & Estande & $\begin{array}{c}\text { Es } m^{-2} \\
\left(n^{o}\right)\end{array}$ & $\begin{array}{c}\text { MMG } \\
(\mathrm{g})\end{array}$ & $\begin{array}{l}\text { Rend. } \\
\left(\mathrm{kg} \mathrm{ha}^{-1}\right)\end{array}$ \\
\hline Testemunha & $2,70 \mathrm{a}$ & $84 \mathrm{a}$ & $9,7 \mathrm{a}$ & $55,3 \mathrm{a}$ & $425 \mathrm{a}$ & $625 \mathrm{a}$ & $37,5 \mathrm{a}$ & $5725 \mathrm{~b}$ \\
\hline TE $1^{\circ}-2^{\circ}$ nó & $2,53 \mathrm{a}$ & $78 \mathrm{~b}$ & $0,9 \mathrm{~b}$ & $14,7 \mathrm{~b}$ & $423 \mathrm{a}$ & $656 a$ & $36,5 \mathrm{a}$ & $6234 \mathrm{a}$ \\
\hline $\operatorname{TE} 2^{\circ}-3^{\circ}$ nó & $2,53 \mathrm{a}$ & $76 \mathrm{~b}$ & $0,0 \mathrm{~b}$ & $4,4 \mathrm{~b}$ & $431 \mathrm{a}$ & $648 \mathrm{a}$ & $36,7 \mathrm{a}$ & $6221 \mathrm{a}$ \\
\hline TE sequencial & $2,48 \mathrm{a}$ & $77 \mathrm{~b}$ & $0,0 \mathrm{~b}$ & $11,6 \mathrm{~b}$ & $422 \mathrm{a}$ & $645 \mathrm{a}$ & $37,2 \mathrm{a}$ & $6015 \mathrm{ab}$ \\
\hline \multicolumn{9}{|l|}{$\mathrm{N}$ em cobertura $(\%)^{1}$} \\
\hline $100\left(90 \mathrm{~kg} \mathrm{ha}^{-1}\right)$ & 2,68 & 78 & 1,7 & 11,1 & 428 & 627 & 37,0 & 5827 \\
\hline $150\left(135 \mathrm{~kg} \mathrm{ha}^{-1}\right)$ & 2,51 & 79 & 3,3 & 17,6 & 426 & 639 & 36,8 & 6160 \\
\hline $200\left(180 \mathrm{~kg} \mathrm{ha}^{-1}\right)$ & 2,49 & 78 & 2,4 & 24,1 & 435 & 661 & 36,5 & 6025 \\
\hline $250\left(225 \mathrm{~kg} \mathrm{ha}^{-1}\right)$ & 2,56 & 79 & 3,3 & 30,6 & 428 & 645 & 37,6 & 6183 \\
\hline Regressão & ns & ns & ns & $\mathrm{L}^{*}$ & ns & ns & ns & ns \\
\hline $\mathrm{CV}(\%)$ & 40,0 & 4,2 & 26,1 & 94,2 & 7,8 & 5,6 & 5,3 & 9,4 \\
\hline Tratamentos & \multicolumn{8}{|c|}{ Cultivar de trigo BRS 177} \\
\hline $\begin{array}{l}\text { Regulador de } \\
\text { crescimento }\end{array}$ & $\begin{array}{l}\mathrm{DC}_{1} \\
(\mathrm{~cm})\end{array}$ & $\begin{array}{l}\text { Est. } \\
(\mathrm{cm})\end{array}$ & $\begin{array}{c}\text { Ac. F } \\
(\%)\end{array}$ & $\begin{array}{c}\text { Ac. PC } \\
(\%)\end{array}$ & Estande & $\begin{array}{c}\text { Es } \mathrm{m}^{-2} \\
\left(\mathrm{n}^{\mathrm{o}}\right)\end{array}$ & $\begin{array}{c}\text { MMG } \\
(\mathrm{g})\end{array}$ & $\begin{array}{c}\text { Rend. } \\
\left(\mathrm{kg} \mathrm{ha}^{-1}\right)\end{array}$ \\
\hline Testemunha & $2,86 \mathrm{a}$ & $100 \mathrm{a}$ & $86,7 \mathrm{a}$ & 98,8 a & $415 \mathrm{a}$ & $605 \mathrm{a}$ & $33,0 \mathrm{a}$ & 4549 a \\
\hline TE $1^{\circ}-2^{\circ}$ nó & $2,82 \mathrm{ab}$ & $89 \mathrm{~b}$ & $30,3 \mathrm{~b}$ & $82,5 \mathrm{bc}$ & $413 \mathrm{a}$ & $609 \mathrm{a}$ & $32,7 \mathrm{a}$ & $4821 \mathrm{a}$ \\
\hline TE $2^{\circ}-3^{\circ}$ nó & $2,77 \mathrm{~b}$ & $82 \mathrm{c}$ & $16,3 \mathrm{~b}$ & $72,8 \mathrm{c}$ & $422 \mathrm{a}$ & $603 \mathrm{a}$ & $32,9 \mathrm{a}$ & $4554 \mathrm{a}$ \\
\hline TE sequencial & $2,79 \mathrm{ab}$ & $87 \mathrm{~b}$ & $25,0 \mathrm{~b}$ & $87,8 \mathrm{ab}$ & $416 \mathrm{a}$ & $612 \mathrm{a}$ & $33,5 \mathrm{a}$ & $4676 \mathrm{a}$ \\
\hline \multicolumn{9}{|l|}{$\mathrm{N}$ em cobertura $(\%)^{1}$} \\
\hline $100\left(60 \mathrm{~kg} \mathrm{ha}^{-1}\right)$ & 2,80 & 90 & 21,3 & 75,7 & 418 & 615 & 34,1 & 4690 \\
\hline $150\left(80 \mathrm{~kg} \mathrm{ha}^{-1}\right)$ & 2,77 & 90 & 33,3 & 82,2 & 416 & 618 & 32,9 & 4623 \\
\hline $200\left(120 \mathrm{~kg} \mathrm{ha}^{-1}\right)$ & 2,81 & 89 & 45,34 & 88,7 & 417 & 632 & 32,4 & 4593 \\
\hline $250\left(150 \mathrm{~kg} \mathrm{ha}^{-1}\right)$ & 2,85 & 90 & 57,3 & 95,2 & 413 & 639 & 32,9 & 4695 \\
\hline Regressão & ns & ns & $\mathrm{L}^{* *}$ & $\mathrm{~L}^{*}$ & ns & ns & ns & ns \\
\hline CV (\%) & 12,6 & 3,9 & 57,6 & 21,7 & 7,2 & 7,6 & 6,9 & 9,8 \\
\hline
\end{tabular}

Médias dos tratamentos com trinexapac-ethyl seguidas da mesma letra nas colunas não diferem significativamente pelo teste de Tukey, a 5\% de probabilidade; ${ }^{1}$ Porcentagem da dose de nitrogênio recomendada por Pauletti \& Costa (2002) e respectiva dose em $\mathrm{kg} \mathrm{ha}^{-1} ; \mathrm{ns}=$ não significativo; $*=$ significativo a $5 \% ; * *=$ significativo a $1 \% ; \mathrm{L}=$ linear; Ac. PC Avante $=0,13 \mathrm{x}-1,88\left(\mathrm{R}^{2}=0,38\right)$; Ac. F BRS $177=-2,66+0,24 x\left(R^{2}=0,48\right)$; Ac. PC BRS $177=62,67+0,13 x\left(R^{2}=0,74\right)$. 
Apesar do número de espigas por $\mathrm{m}^{2}$ e da massa de mil grãos não terem sido influenciados pelo redutor, o seu uso promoveu aumento do rendimento de grãos para a cultivar Avante, tanto para a aplicação entre primeiro e segundo nó como segundo e terceiro nó visível, mas não para a aplicação sequencial. O rendimento de grãos da cultivar Avante com o uso do redutor foi superior a $6.000 \mathrm{~kg} \mathrm{ha}^{-1}$, independentemente da época de aplicação, sendo superior à média do estado do Paraná, que foi de $2.253 \mathrm{~kg} \mathrm{ha}^{-1}$ para a safra 2003 (Secretaria de Estada da Agricultura e do Abastecimento - SEAB, 2006). Na cultivar BRS 177, o redutor não promoveu diferenças no rendimento de grãos (Tabela 1), porém, a média obtida também foi superior à do Estado na mesma safra. Os elevados rendimentos de grãos obtidos nesse experimento evidenciam que o clima e o manejo são decisivos na determinação do rendimento de grãos. O aumento do rendimento de grãos com o uso de redutores de crescimento vem sendo observado por vários autores (Matysiak, 2006; Zagonel \& Fernandes, 2007; Borm \& Berg, 2008), embora seu uso tenha como objetivo a redução do acamamento. Penckowski \& Fernandes (2010) atribuem esse aumento de produção, pelo uso do trinexapac-ethyl, às mudanças na arquitetura foliar das plantas, especialmente da angulação da folha bandeira, que fica mais ereta. $\mathrm{O}$ aumento da dose de nitrogênio não promoveu aumento no rendimento de grãos em ambas as cultivares, mostrando que a dose de $60 \mathrm{~kg} \mathrm{ha}^{-1}$ para a cultivar BRS 177 e $90 \mathrm{~kg} \mathrm{ha}^{-1}$ para a Avante são suficientes para a exteriorização do potencial produtivo das cultivares.

A qualidade industrial é uma das exigências das indústrias moageiras e panificadoras e dos produtores de grãos de trigo. O peso do hectolitro $(\mathrm{PH})$ e o "Falling Number" referem-se à qualidade dos grãos, enquanto as demais características referem-se à qualidade da farinha. O PH da cultivar Avante não sofreu influência do redutor (Tabela 2) e mostrou valor inferior ao da média da cultivar, que é de 78,1 kg hL-1 (Campos et al., 2004). Para a cultivar BRS 177, o PH foi influenciado pelos tratamentos com trinexapac-ethyl e os valores obtidos foram superiores ao da testemunha sem aplicação do redutor, mas abaixo da média dessa cultivar, que é de $77,0 \mathrm{~kg} \mathrm{hL}^{-1}$ (Campos et al., 2004). O aumento do PH na cultivar mais suscetível ao acamamento (BRS 177) com o uso de redutor de crescimento pode ser explicado pela redução do acamamento e da estatura das plantas. As doses de N não influenciaram o PH da cultivar Avante, assim como observado por Teixeira Filho et al. (2007), em diferentes cultivares de trigo. Entretanto, o aumento da dose de $\mathrm{N}$ promoveu uma redução linear do $\mathrm{PH}$ na cultivar BRS 177, resultado similar ao de Cánovas \& Trindade (2003) que observaram resposta decrescente do PH com o aumento do nitrogênio. O "Falling Number" não foi influenciado pela época de aplicação do redutor de crescimento nas duas cultivares (Tabela 2), em razão do clima sem excessos de precipitação e das cultivares Avante e BRS 177 serem classificadas, respectivamente, como moderadamente resistente e moderadamente tolerante à germinação na espiga (Campos et al., 2004). $\mathrm{O}$ aumento das doses de $\mathrm{N}$ não influenciou o "Falling Number" da cultivar Avante, o que também foi observado por Guarienti et al. (1999) e Scalco et al. (2002). Para a cultivar BRS 177, o aumento na dose de N resultou em menor "Falling Number", até um limite (Tabela 2). Portanto, o nitrogênio pode afetar a qualidade do grão, em que os melhores índices de PH e "Falling Number" ocorrem nas menores doses de $\mathrm{N}$.

Com relação à qualidade da farinha, a porcentagem de glúten, tanto úmido como seco, não foi influenciada pelos tratamentos com trinexapac-ethyl nas cultivares Avante e BRS 177 (Tabela 2). Os níveis de glúten úmido e seco foram superiores a $30 \%$ e $10 \%$, respectivamente, o que torna essa farinha adequada para fabricação de pães franceses, visto que os valores de glúten úmido deverão ser superiores a $28 \%$ e seco acima de $9 \%$ (Serviço Brasileiro de Respostas Técnicas - SBRT, 2006). O aumento da dose de $\mathrm{N}$ não afetou os níveis de glúten úmido e seco na cultivar Avante, mas promoveu um aumento na cultivar BRS 177, até um limite.

Com relação à alveografia (Tabela 2), os tratamentos com redutor de crescimento não influenciaram a tenacidade (P) nas duas cultivares. O uso do redutor promoveu aumento da extensibilidade (L) na cultivar BRS 177, indicando que essa farinha produzirá pães de volume maior. A relação $\mathrm{P} / \mathrm{L}$ foi menor somente com a aplicação do redutor entre o $1^{\circ}$ e $2^{\circ}$ nó visível, na cultivar BRS 177. A força de glúten (W) para a cultivar Avante não sofreu influência do redutor, mas, para a BRS 177 influenciou a força de glúten, em que a aplicação sequencial resultou no maior valor de W. Em ambas as cultivares os valores de W estiveram dentro da classificação de Campos et al. (2004) para cada cultivar e esses trigos foram classificados como "tipo pão". As doses de $\mathrm{N}$ não influenciaram as características da alveografia. 
Tabela 2 - Efeito do trinexapac-ethyl (TE) e do nitrogênio $(\mathrm{N})$ na qualidade dos grãos através do peso do hectolitro (PH) e do "Falling Number" (FN); na qualidade da farinha através da porcentagem de glúten úmido (Glut. U) e glúten seco (Glut. S); e da alveografia da farinha através da tenacidade (P), extensibilidade (L), relação tenacidade/extensibilidade (P/L) e força de glúten (W), nas cultivares de trigo Avante e BRS 177.

\begin{tabular}{|c|c|c|c|c|c|c|c|c|}
\hline \multirow{3}{*}{$\begin{array}{l}\text { Tratamentos } \\
\text { Regulador de } \\
\text { crescimento }\end{array}$} & \multicolumn{8}{|c|}{ Cultivar de trigo Avante } \\
\hline & \multicolumn{2}{|c|}{ Qualid. do grão } & \multicolumn{2}{|c|}{ Qualid. da farinha } & \multicolumn{4}{|c|}{ Alveografia } \\
\hline & $\begin{array}{c}\mathrm{PH} \\
\left(\mathrm{kg} \mathrm{hL}^{-1}\right)\end{array}$ & $\begin{array}{l}\text { FN } \\
(s)\end{array}$ & $\begin{array}{c}\text { Glut. U } \\
(\%)\end{array}$ & $\begin{array}{c}\text { Glut. S } \\
(\%)\end{array}$ & $\begin{array}{c}\mathrm{P} \\
(\mathrm{mm})\end{array}$ & $\begin{array}{c}\mathrm{L} \\
(\mathrm{mm})\end{array}$ & $\mathrm{P} / \mathrm{L}$ & $\begin{array}{c}\mathrm{W} \\
\left(10^{-4} \mathrm{~J}\right)\end{array}$ \\
\hline Testemunha & $76,1 \mathrm{a}$ & $317 \mathrm{a}$ & $31,9 \mathrm{a}$ & $10,6 \mathrm{a}$ & $51,3 \mathrm{a}$ & $103,8 \mathrm{a}$ & $0,5 \mathrm{a}$ & $204 \mathrm{a}$ \\
\hline TE $1^{\circ}-2^{\circ}$ nó & $74,9 \mathrm{a}$ & $312 \mathrm{a}$ & 32,9 a & $10,8 \mathrm{a}$ & 58,9 a & 100,6 a & $0,4 \mathrm{a}$ & $205 \mathrm{a}$ \\
\hline TE $2^{\circ}-3^{\circ}$ nó & $76,7 \mathrm{a}$ & $310 \mathrm{a}$ & $33,2 \mathrm{a}$ & $11,2 \mathrm{a}$ & $65,9 \mathrm{a}$ & $114,6 \mathrm{a}$ & $0,5 \mathrm{a}$ & $200 \mathrm{a}$ \\
\hline TE sequencial & $76,5 \mathrm{a}$ & $302 \mathrm{a}$ & $32,1 \mathrm{a}$ & $10,7 \mathrm{a}$ & 56,0 a & $111,7 \mathrm{a}$ & $0,5 \mathrm{a}$ & $214 \mathrm{a}$ \\
\hline \multicolumn{9}{|l|}{$\mathrm{N}$ em cobertura $(\%)^{1}$} \\
\hline $100\left(90 \mathrm{~kg} \mathrm{ha}^{-1}\right)$ & 76,9 & 306 & 31,5 & 10,6 & 48,9 & 112,6 & 0,5 & 211 \\
\hline $150\left(135 \mathrm{~kg} \mathrm{ha}^{-1}\right)$ & 76,1 & 301 & 32,5 & 10,6 & 60,7 & 117,3 & 0,5 & 197 \\
\hline $200\left(180 \mathrm{~kg} \mathrm{ha}^{-1}\right)$ & 76,4 & 309 & 32,3 & 10,8 & 48,1 & 102,5 & 0,5 & 195 \\
\hline $250\left(225 \mathrm{~kg} \mathrm{ha}^{-1}\right)$ & 75,0 & 314 & 33,0 & 11,3 & 52,4 & 104,1 & 0,5 & 200 \\
\hline Regressão & ns & ns & Ns & Ns & Ns & ns & Ns & ns \\
\hline $\mathrm{CV}(\%)$ & 3,5 & 18,3 & 8,4 & 9,7 & 23,4 & 25,6 & 12,7 & 18,9 \\
\hline \multirow{2}{*}{ Tratamentos } & \multicolumn{8}{|c|}{ Culivar de trigo BRS 177} \\
\hline & \multicolumn{2}{|c|}{ Qualid. do grão } & \multicolumn{2}{|c|}{ Qualid. da farinha } & \multicolumn{4}{|c|}{ Alveografia } \\
\hline $\begin{array}{l}\text { Regulador de } \\
\text { crescimento }\end{array}$ & $\begin{array}{c}\mathrm{PH} \\
\left(\mathrm{kg} \mathrm{hL}^{-1}\right)\end{array}$ & $\begin{array}{l}\text { FN } \\
(\mathrm{s})\end{array}$ & $\begin{array}{c}\text { Glut. U } \\
(\%)\end{array}$ & $\begin{array}{c}\text { Glut. S } \\
(\%)\end{array}$ & $\begin{array}{c}\mathrm{P} \\
(\mathrm{mm})\end{array}$ & $\begin{array}{c}\mathrm{L} \\
(\mathrm{mm})\end{array}$ & $\mathrm{P} / \mathrm{L}$ & $\begin{array}{c}\mathrm{W} \\
\left(10^{-4} \mathrm{~J}\right) \\
\end{array}$ \\
\hline Testemunha & $74,5 \mathrm{~b}$ & $317 \mathrm{a}$ & $31,1 \mathrm{a}$ & $10,4 \mathrm{a}$ & $56,2 \mathrm{a}$ & $78,9 \mathrm{~b}$ & $0,7 \mathrm{a}$ & $198 \mathrm{c}$ \\
\hline TE $1^{\circ}-2^{\circ}$ nó & $75,9 \mathrm{a}$ & $309 \mathrm{a}$ & 33,9 a & $11,5 \mathrm{a}$ & $52,0 \mathrm{a}$ & $99,2 \mathrm{a}$ & $0,5 \mathrm{~b}$ & $210 \mathrm{~b}$ \\
\hline TE $2^{\circ}-3^{\circ}$ nó & 75,9 a & $315 \mathrm{a}$ & $33,2 \mathrm{a}$ & $10,4 \mathrm{a}$ & $57,9 \mathrm{a}$ & $95,7 \mathrm{a}$ & 0,6 a & $194 \mathrm{c}$ \\
\hline TE sequencial & $76,2 \mathrm{a}$ & $323 \mathrm{a}$ & $31,4 \mathrm{a}$ & $10,5 \mathrm{a}$ & 59,3 a & $103,4 \mathrm{a}$ & $0,6 \mathrm{a}$ & $254 \mathrm{a}$ \\
\hline \multicolumn{9}{|l|}{$\mathrm{N}$ em cobertura $(\%)^{1}$} \\
\hline $100\left(60 \mathrm{~kg} \mathrm{ha}^{-1}\right)$ & 76,8 & 325,0 & 27,3 & 9,3 & 54,5 & 92,1 & 0,6 & 206 \\
\hline $150\left(80 \mathrm{~kg} \mathrm{ha}^{-1}\right)$ & 76,1 & 317,5 & 28,1 & 10,4 & 58,2 & 99,4 & 0,6 & 230 \\
\hline $200\left(120 \mathrm{~kg} \mathrm{ha}^{-1}\right)$ & 75,4 & 312,2 & 26,7 & 11,4 & 58,0 & 89,0 & 0,6 & 212 \\
\hline $250\left(150 \mathrm{~kg} \mathrm{ha}^{-1}\right)$ & 74,7 & 308,9 & 23,2 & 11,0 & 58,9 & 96,1 & 0,6 & 234 \\
\hline Regressão & $\mathrm{L}^{* *}$ & $\mathrm{Q}^{* *}$ & $\mathrm{Q}^{*}$ & $\mathrm{Q}^{* *}$ & Ns & $\mathrm{ns}$ & Ns & $\mathrm{ns}$ \\
\hline $\mathrm{CV}(\%)$ & 2,4 & 8,5 & 7,2 & 6,3 & 8,8 & 8,3 & 3,5 & 14,2 \\
\hline
\end{tabular}

Médias dos tratamentos com trinexapac-ethyl seguidas da mesma letra nas colunas não diferem significativamente pelo teste de

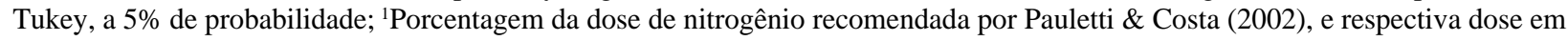
$\mathrm{kg} \mathrm{ha}^{-1}$; ns = não significativo; $*$ significativo a 5\%; $* *=$ significativo a $1 \% ; \mathrm{L}=$ linear; $\mathrm{Q}=$ quadrática; $\mathrm{PH} \mathrm{BRS} 177=-0,015 \mathrm{x}+$ $78,36\left(R^{2}=0,87\right)$; FN BRS $177=0,00043 x^{2}-0,26 x+346,25\left(R^{2} 0,80\right)$; Glut. U BRS $177=-0,00043 x^{2}+0,123 x+19,3\left(R^{2} 0,78\right)$; Glut. S BRS $177=-0,000150 x^{2}+0,0647 x+4,265\left(R^{2} 0,81\right)$.

\section{CONCLUSÕES}

O trinexapac-ethyl reduz a estatura das plantas e o acamamento, independentemente da época de aplicação.
Na cultivar Avante, a aplicação de trinexapac-ethyl nas fases de $1^{\circ}$ e $2^{\circ}$ nó visível ou $2^{\circ}$ e $3^{\circ}$ nó visível promove aumento do rendimento de grãos. 
A qualidade do grão de trigo e da farinha não são influenciadas de forma substancial pela aplicação de trinexapac-ethyl.

A dose de $60 \mathrm{~kg} \mathrm{ha}^{-1}$ de N para a cultivar BRS $177 \mathrm{e}$ $90 \mathrm{~kg} \mathrm{ha}^{-1}$ para a cultivar Avante são indicadas para a região dos Campos Gerais e suprem as necessidades das cultivares, mesmo em altos rendimentos de grãos.

O aumento da dose de nitrogênio aumenta a força de glúten e quantidade de glúten úmido e seco, e diminui o peso do hectolitro e "Falling Number" para cultivar BRS 177.

\section{REFERÊNCIAS BIBLIOGRÁFICAS}

BERTI, M.; ZAGONEL, J.; FERNANDES, E.C. Produtividade de cultivares de trigo em função do trinexapac-ethyl e doses de nitrogênio. Scientia Agrária, Curitiba, v.8, n.2, p.127-134, 2007.

BORM, G.E.L.; BERG, W. van den. Effects of the application rate and time of the growth regulator trinexapac-ethyl in seed crops of Lolium perenne L. in relation to spring nitrogen rate. Field Crops Research, Amsterdam, v.105, n.3, p.182-192, 2008.

CAMPOS, L.A.; DOTTO, S.R.; BRUNETTA, D. Informações técnicas da comissão centro-sul brasileira de pesquisa de trigo e de triticale para safra de 2004. Londrina: Embrapa/Iapar, 2004. 214p. (Documentos, 1).

CÁNOVAS, A.D.; TRINDADE, M. da G. Efeito de níveis de nitrogênio e frequência de aplicação de água na produtividade e na aptidão industrial do trigo. Santo Antônio de Goiás: Embrapa Arroz e Feijão, 2003. 2p. (Comunicado técnico, 70).

DAVIES, P.J. The plant hormones: their nature, occourrence, and functions. In: DAVIES, P.J. (Ed.). Plant hormones and their role in plant growth and development. Nethrlands: Kluwer Academic, 1987. p.1-23.

EMPRESA BRASILEIRA DE PESQUISA AGROPECUÁRIA. Cultivares de trigo. Passo Fundo: Embrapa Trigo, 2008. Disponível em: <http:// WwW.cnpt.embrapa.br/culturas/trigo/cultivaresh index.htm>. Acesso em: 20 jun. 2008.

EMPRESA BRASILEIRA DE PESQUISA AGROPECUÁRIA. Sistema brasileiro de classificação de solos. 2.ed. Brasília, 2006. 306p.
GUARIENTI, E.M. Qualidade industrial do trigo. Passo Fundo: Embrapa-CNPT, 1996. 36p. (Documentos, 27).

GUARIENTI, E.M.; SANTOS, H.P. dos; LHAMBY, J.C.B. Influência do manejo do solo e da rotação de culturas na qualidade industrial do trigo. Pesquisa Agropecuária Brasileira, Brasília, v.35, n.12, p.2375-2382, 2000.

GUTKOSKI, L.C.; KLEIN, B.; PAGNUSSATT, F.A.; PEDÓ, I. Características tecnológicas de genótipos de trigo (Triticum aestivum L.) cultivados no cerrado. Ciência e Agrotecnologia, Lavras, v.31, n.3, p.786-792, 2007.

LOZANO, C.M.; LEADEN, M.I.;COLABELLI, M.N. Efecto de Trinexapac ethyl sobre la morfología del tallo en dos cultivares de trigo. Buenos Aires: INTA EEA Balcare, 2002. Disponível em: <http://www.inta.gov.ar/ ibalcarce/info/documentos/posters $/ 5$ / MorfoldelTalloLeaden.htm, A Acesso em: 12 ago. 2006

MATYSIAK, K. Influence of trinexapac-ethyl on growth and development of winter wheat. Journal of Plant Protection Research, Poznan, v.46, n.2, p.133-143, 2006.

MEGDA, M.M.; BUZETTI, S.; ANDREOTTI, M.; TEIXEIRA FILHO, M.M.C.; VIEIRA, M.X. Resposta de cultivares de trigo ao nitrogênio em relação às fontes e épocas de aplicação sob plantio direto e irrigação por aspersão. Ciência e Agrotecnologia, Lavras, v.33, n.4, p.1055-1060, 2009.

OLIVEIRA, E.L. de. Sugestão de adubação e calagem para culturas de interesse econômico no Estado do Paraná. Londrina: IAPAR, 2003. 30p.

PAULETTI, V.; COSTA, L.C. Calibração de doses de nitrogênio para trigo em plantio direto. Castro: Fundação ABC, 2002. Relatório interno.

PENCKOWSKI, L.H.; FERNANDES, E.C. Utilizando regulador de crescimento na cultura de trigo: aspectos importantes para garantir bons resultados. 3.ed. Castro: Fundação ABC, 2010. 68p.

PIZZINATTO, A. Qualidade da farinha de trigo: conceitos, fatores determinantes, parâmetros de avaliação e controle. Campinas: ITAL, 1997. 62p.

RADEMACHER, W. Growth retardants: effects on gibberellin biosynthesis and other metabolic pathways. Annual Review of Plant Physiology and Plant Molecular Biology, Palo Alto, v.51, p.501-531, 2000. 
RODRIGUES, O.; DIDONETE, A.D.; TEIXEIRA, C.C.M.; ROMAM, S.E. Redutores de crescimento. Passo Fundo: Embrapa Trigo, 2003. (Circular técnica, 14).

SCALCO, M.S.; FARIA, M.A. de; GERMANI, R.; MORAIS, A.R. de. Produtividade e qualidade industrial do trigo sob diferentes níveis de irrigação e adubação. Ciência e Agrotecnologia, Lavras, v.26, n.2, p.400-410, 2002.

\section{SECRETARIA DE ESTADA DA AGRICULTURA E DO} ABASTECIMENTO. Área colhida, produção e produtividade, por cultura, safra 03/04. Disponível em: <http:///www.seab.pr.gov.br/arguivos/File/deral ilpa0304.xls>. Acesso em: 10 mar. 2006.

\section{SERVIÇO BRASILEIRO DE RESPOSTAS TÉCNICAS.}

Massas alimentícias. Disponível em: <http://

isbrtvi.ibict.br/upload/sbrt237 2 pdfrs. Acesso em: $10 \mathrm{mar}$. 2006.

SILVA, D.B.; GOTTO, W.S. Resposta do trigo de sequeiro ao nitrogênio, após soja precoce, na região do Alto Paranaíba, MG. Pesquisa Agropecuária Brasileira, Brasília, v.26, n.9, p.1401-1405, 1990.
TEIXEIRA, C.C.M.; RODRIGUES, O. Efeito da adubação nitrogenada, arranjo de plantas e redutor de crescimento no acamamento e em características de cevada. Passo Fundo: Embrapa Trigo, 2003. 16p. (Boletim de Pesquisa e Desenvolvimento, 20).

TEIXEIRA FILHO, M.C.M.; BUZETTI, S.; ALVAREZ, R. de C.F.; FREITAS, J.G. de; ARF, O.; SÁ, M.E. de. Resposta de cultivares de trigo irrigados por aspersão ao nitrogênio em cobertura na região do Cerrado. Acta Scientiarum. Agronomy, Maringá, v.29, n.3, p.421-425, 2007.

ZADOKS, J.C.; CHANG, T.T.; KONZAK, C.F. A decimal code for the growth stages of cereals. Weed Research, Oxford, v.14, p.415-421, 1974.

ZAGONEL, J.; FERNANDES, E.C. Doses e épocas de aplicação de redutor de crescimento afetando cultivares de trigo em duas doses de nitrogênio. Planta Daninha, Viçosa, v.25, n.2, p.331-339, 2007.

ZAGONEL, J.; VENANCIO, W.S.; KUNZ, R.P.; TANAMATI, H. Doses de nitrogênio e densidades de plantas com e sem um regulador de crescimento afetando o trigo, cultivar OR 1. Ciência Rural, Santa Maria, v.32, n.1, p.25-29, 2002. 